\title{
EFFECT OF FREQUENCY ON MW ASSISTED SINTERING: 2.45 GHZ VERSUS 5.8 GHZ
}

L. Gil-Flores*(1), M. D. Salvador ${ }^{(1)}$, F. L. Penaranda-Foix ${ }^{(2)}$, A. Fernández ${ }^{(3)}$, M. Suarez $^{(3)}$, R. Rosa ${ }^{(4)}$, P. Veronesi ${ }^{(4)}$, C. Leonelli ${ }^{(4)}$, A. Borrell $^{(1)}$

${ }^{(1)}$ Instituto de Tecnología de Materiales, Universitat Politècnica de València, Camino de Vera s/n, 46022, Valencia, Spain

${ }^{(2)}$ Instituto de Aplicaciones de las Tecnologías de la Información y de las Comunicaciones Avanzadas (ITACA), Universitat Politècnica de València, Camino de Vera s/n, 46022, Valencia, Spain

${ }^{(3)}$ Centro de Investigación en Nanomateriales y Nanotecnología (CINN) (CSIC-UOPA), Avenida de la Vega 4-6, 33940 El Entrego (Asturias), Spain

${ }^{(4)}$ MAG_Microwave Application Group, Dipartimento di Ingegneria "Enzo Ferrari”, Università degli Studi di Modena e Reggio Emilia, Via P. Vivarelli 10, 41125 Modena, Italy

*Corresponding author: Instituto de Tecnología de Materiales (ITM), Universitat Politècnica de València, Camino de Vera $\mathrm{s} / \mathrm{n}$, 46022, Valencia, Spain. Tel.: +34963877007; Fax: +34963877629. E-mail address: logiflo@upv.es

ABSTRACT. Innovative non-conventional approaches, such microwave sintering, are being developed as method for sintering a variety of materials which shown advantages against conventional sintering procedures. This work involves an investigation of microwave sintering of ATZ composite with two different microwave applicators and frequency generators: $2.45 \mathrm{GHz}$ and $5.8 \mathrm{GHz}$. Zirconia doped with ceria and toughened with alumina $\left(10 \mathrm{Ce}-\mathrm{TZP} / \mathrm{Al}_{2} \mathrm{O}_{3}\right)$ is the used composite in this study. The samples were sintered by microwave in air at 1200 and $1300{ }^{\circ} \mathrm{C}$ with $10 \mathrm{~min}$ of dwell time at 2.45 and $5.8 \mathrm{GHz}$ in order to evaluate their effects on sintering, using optimized experimental setup. Moreover, the mechanical properties of MW-sintered samples were compared with those obtained for the same composites sintered by conventional method $\left(1500{ }^{\circ} \mathrm{C} / 120\right.$ min), such as relative density, hardness and fracture toughness.

\section{INTRODUCTION}

In the biomaterials field, the design and development of innovative technologies has been motivated by the increasing demand for materials capable to support new specifications and the need of reducing processing times and costs. Zirconia-based composites are commonly used for developing metal-free restorations and dental implants because of its superb mechanical properties, bio-compatibility and aesthetics $[3,4,14]$.

In this work, tetragonal zirconia polycrystalline (TZP) is stabilized with cerium oxide $\left(\mathrm{CeO}_{2}\right)$, a less known dopant, as the commonly used for the stabilization of zirconia is yttrium oxide. With the use of $\mathrm{CeO}_{2}$ as a stabilizer, it is possible to improve the fracture toughness and reduce the low hydrothermal degradation (LTD) suffered by the TZP sample [11]. Low hydrothermal degradation is considered a big problem for biomaterials, especially zirconia is prone to ageing in presence of water [5].

In addition to the choice for appropriate material, another way to improve its properties is by modifying the sintering mechanisms. Adopting a non-conventional sintering methods, such as microwave technique, which has certain advantages compared to the conventional one [7]. 
Microwave processing eliminates the need for spending energy to heat the walls of furnace or reactors, their massive components and heat carriers. Hence, the use of microwave heating significantly reduces energy consumption, particularly in high temperature processes, since heat losses escalate considerably as processing temperatures increase. Heating processes involved in conventional and microwave sintering are completely different since in conventional sintering heat flows from the surface of the material to its interior. In microwave sintering heat is generated within the material core, flowing from the inside to the surface; what is known as volumetric heating $[1,6,12]$. One of the most important parameters within microwave sintering are the dielectric properties of the material, as the amount of absorption of the sample is influenced by them. However, the dielectric properties are not constant and vary depending on of the frequency used [10].

In short, the main objective of this study is to obtain highly densified samples of 10 mol\% $\mathrm{CeO}_{2}$ doped $\mathrm{TZP} / \mathrm{Al}_{2} \mathrm{O}_{3}\left(10 \mathrm{Ce}-\mathrm{TZP} / \mathrm{Al}_{2} \mathrm{O}_{3}\right)$ by microwave sintering using two different frequencies: 2.45 and $5.8 \mathrm{GHz}$.

\section{MATERIALS AND METHODS}

\section{Sample preparation}

The starting powders used in the preparation of the nanocomposites were 10Ce-TZP $\left(\mathrm{ZrO}_{2}\right.$ with $10 \mathrm{~mol}_{0} \mathrm{CeO}_{2}$ ) provided by Daiichi Kigenso Kagaku Kogyo with the commercial name 10Ce-ZP, and alumina SPA 0.5 from Sasol. The studied proportion of this powders is 65 vol. $\%$ of $10 \mathrm{Ce}-\mathrm{TZP}$ and 35 vol. $\% \mathrm{Al}_{2} \mathrm{O}_{3}\left(10 \mathrm{Ce}-\mathrm{TZP} / \mathrm{Al}_{2} \mathrm{O}_{3}\right)$.

Green samples were uniaxially pressed with a press Shimadzu AG-X Plus in order to obtain cylindrical bodies with $10 \mathrm{~mm}$ in diameter and $3 \mathrm{~mm}$ in height. The green samples were sintered in air using microwave technology (MW) at $1200^{\circ} \mathrm{C}$ and $1300{ }^{\circ} \mathrm{C}$ with a heating rate of $60{ }^{\circ} \mathrm{C} / \mathrm{min}$ and $10 \mathrm{~min}$ of holding time at the final temperature with two different frequencies: $2.45 \mathrm{GHz}$ and $5.8 \mathrm{GHz}$. The specimens were also densified by conventional sintering (CS) at $1500{ }^{\circ} \mathrm{C}$ with a heating rate of $10^{\circ} \mathrm{C} / \mathrm{min}$ and $120 \mathrm{~min}$ of dwell time at the final temperature. Conventional sintering was performed in an electrical furnace (Thermolyne type 46100).

\section{Microwave cavities}

Microwave sintering (MW) was performed in two microwave systems operating at two different magnetron frequencies, 2.45 and $5.8 \mathrm{GHz}$, respectively. The first one is a singlemode cylindrical cavity operating in the TE 111 mode with a resonant frequency of 2.45 $\mathrm{GHz}$ (Figure 1a). In this case, the temperature has been measured with an optical pyrometer, previously calibrated in this temperature range. The cavity has one $30-\mathrm{mm}-$ diameter hole on the top that allows the access for a quartz tube containing the specimen (radius $=10 \mathrm{~mm}$, height $=3 \mathrm{~mm}$ ) and a $12-\mathrm{mm}$-diameter hole in lateral wall for a temperature sensor. The dimension and position of these holes were designed to ensure that there was no microwave leakage from the cavity and there was negligible perturbation of the resonant mode. The E field vectors are perpendicular to the cavity axis with the maximum electric field magnitude at the center, where the sample is located. A movable short circuit at the bottom of the cavity permits to track the cavity heating mode resonant variations caused by changes in the dielectric properties of the heated test sample during the sintering process [2]. The second microwave cavity is a single-mode applicator at $5.8 \mathrm{GHz}$ based on the rectangular waveguide geometry (WR159) short circuited by a movable plunger (Figure 1b). 
a)

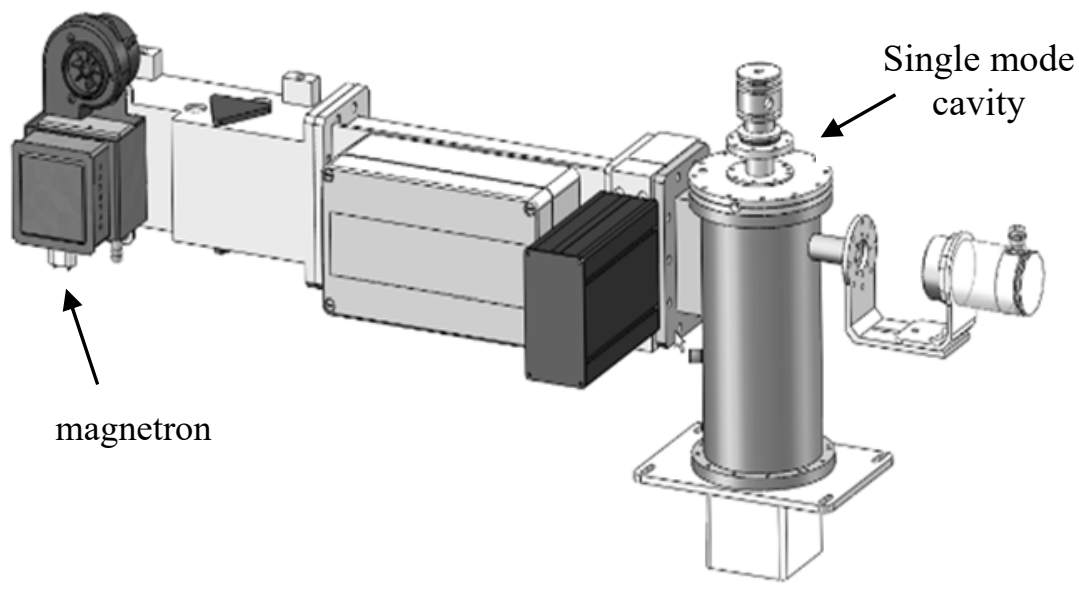

b)

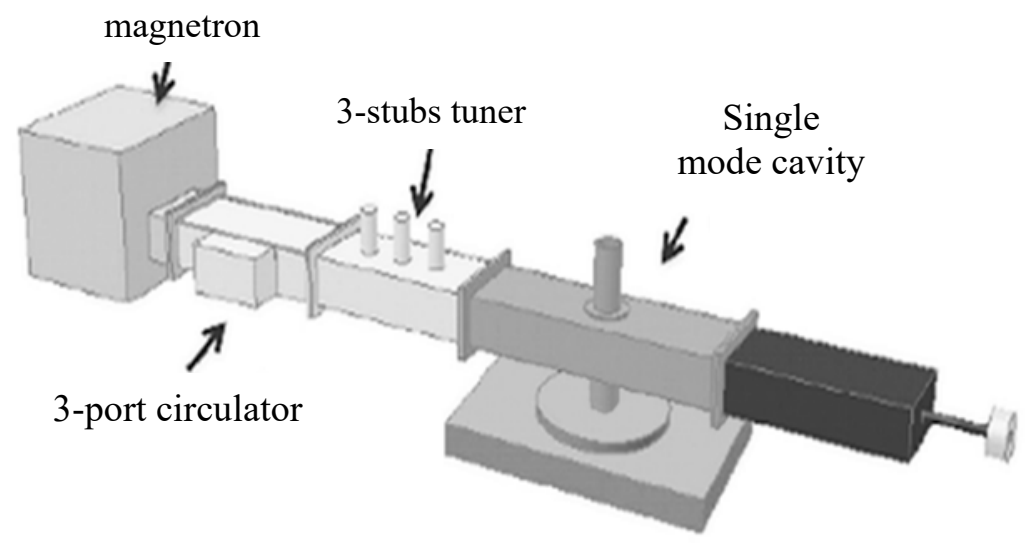

Figure 1. Microwave system at (a) $2.45 \mathrm{GHz}$ and (b) $5.8 \mathrm{GHz}$.

Microwave furnace was equipped with directional couplers, which allowed for the realtime measurement of the emitted and reflected power and hence, by difference, the power dissipated into the load. Temperature was monitored during the microwave processing using a sapphire fiber directly touching the upper free surface of the sample and connected to a signal conditioner (MIKRON M680 Infraducer, Mikron Infrared Inc., CA, USA). A specific temperature detection procedure was applied to reach a correct monitoring of the sintering cycle, optimized at Microwave Application Group at University of Modena and Reggio Emilia, Italy [15].

\section{Mechanical properties and microstructural characterization}

Some physical and mechanical properties were measured for the sintered samples. The bulk density was quantified by Archimedes' principle. Nanohardness and Young' modulus assessments were carried out using a nanoindenter (G-200; Agilent Technologies, Barcelona, Spain) with a Berkovich tip previously calibrated with silica standard [9]. Regarding fracture toughness, $K_{\mathrm{IC}}\left[\mathrm{MPa}^{1 / 2}\right]$, it was estimated by the indentation-fracture method using the following equation of Evans: 


$$
K_{I C}=0.16 \cdot\left(\frac{c}{a}\right)^{-1.5} \cdot H_{V} \cdot a^{0.5}
$$

where $H_{V}$ is the Vickers hardness and $a[\mathrm{~m}]$ and $c[\mathrm{~m}]$ is the half length of the Vickers impression and the Palmqvist crack, respectively. The applied load in this test was $20 \mathrm{Kg}$ for $15 \mathrm{~s}$ in a Centaur HD9-45 (Metrol Centaur, S.L., Bilbao, Spain).

\section{RESULTS AND DISCUSSION}

All relative densities values of MW and CS sintered samples are above $98 \%$, as can be seen in Table 1. For density estimation, it has been taken $5.06 \mathrm{~g} / \mathrm{cm}^{3}$ as theoretical density for the studied composite $10 \mathrm{Ce}-\mathrm{TZP} / \mathrm{Al}_{2} \mathrm{O}_{3}$. From these values, it can be extracted that the relative densities increase steadily from 98.5 to $99.5 \%$ with the rise of sintering temperature.

Table 1. Summary of the sintering parameter and relative density determined for $10 \mathrm{Ce}-\mathrm{TZP} / \mathrm{Al}_{2} \mathrm{O}_{3}$ after conventional and microwave sintering.

\begin{tabular}{|c|c|c|c|}
\hline \multicolumn{3}{|c|}{ Sintering conditions } & \multirow{2}{*}{$\begin{array}{c}\text { Relative } \\
\text { Density } \\
(\%)\end{array}$} \\
\hline $\begin{array}{l}\text { Temperature } \\
\left({ }^{\circ} \mathrm{C}\right)\end{array}$ & $\begin{array}{l}\text { Dwell time } \\
\text { (min) }\end{array}$ & $\begin{array}{l}\text { Technique } \\
\text { (MW/CS) }\end{array}$ & \\
\hline \multirow{2}{*}{1200} & \multirow{2}{*}{10} & MW $2.45 \mathrm{GHz}$ & $98.7 \pm 0.4$ \\
\hline & & MW $5.8 \mathrm{GHz}$ & $99.2 \pm 0.4$ \\
\hline \multirow{2}{*}{1300} & \multirow{2}{*}{10} & MW $2.45 \mathrm{GHz}$ & $99.0 \pm 0.4$ \\
\hline & & MW $5.8 \mathrm{GHz}$ & $99.5 \pm 0.4$ \\
\hline 1500 & 120 & $\mathrm{CS}$ & $99.3 \pm 0.4$ \\
\hline
\end{tabular}

The composites sintered at $2.45 \mathrm{GHz}$ show a slight lower density than those sintered using $5.8 \mathrm{GHz}$. An increase in microwave frequency can lead to an improvement in the absorption of microwaves by the ceramic material, therefore more energy is transmitted to the material. When both sintering technologies are compared, microwave and conventional sintering, the density of microwave-sintered materials are higher (from $98.7 \%$ at $1200{ }^{\circ} \mathrm{C}-10$ min with $2.45 \mathrm{GHz}$ to $99.5 \%$ at $1300{ }^{\circ} \mathrm{C}-10$ min with $5.8 \mathrm{GHz}$ ) even if they were processed at lower temperature and sintering times than material conventionally densified. Therefore, a remarkable result is that microwave sintering allows to obtain highly sintered samples at considerably lower temperature and less processing time than conventional sintering method.

Regarding mechanical properties, the results agree with the relative density values that have been calculated. The hardness values obtained as a function of heating mode and frequency are presented in Figure 2.

By microwave sintering at $2.45 \mathrm{GHz}$, the hardness of the composites at 1200 and 1300 ${ }^{\circ} \mathrm{C}$ is slightly lower $(\sim 13 \mathrm{GPa})$ with respect to the values obtained at $5.8 \mathrm{GHz}$ of frequency (14.2 and 14.6 GPa for 1200 and $1300{ }^{\circ} \mathrm{C}$, respectively). The latter is closed to the maximum hardness value obtained in this work $(15.1 \mathrm{GPa})$ that corresponds to the sample prepared by conventional sintering at $1500{ }^{\circ} \mathrm{C}$. Then, it is observed that $\mathrm{MW}$-sintered samples show Hv values comparable to conventionally sintered samples despite they have been sintered for shorter times at a much lower temperature. 
Another mechanical property, which has a very important role in bioceramics, is fracture toughness, $\mathrm{K}_{\mathrm{IC}}$. In Figure 3, it can be seen the values of $\mathrm{K}_{\mathrm{IC}}$ for $10 \mathrm{Ce}-\mathrm{TZP} / \mathrm{Al}_{2} \mathrm{O}_{3}$ sintered at different temperatures by conventional and microwave as a function of frequency.

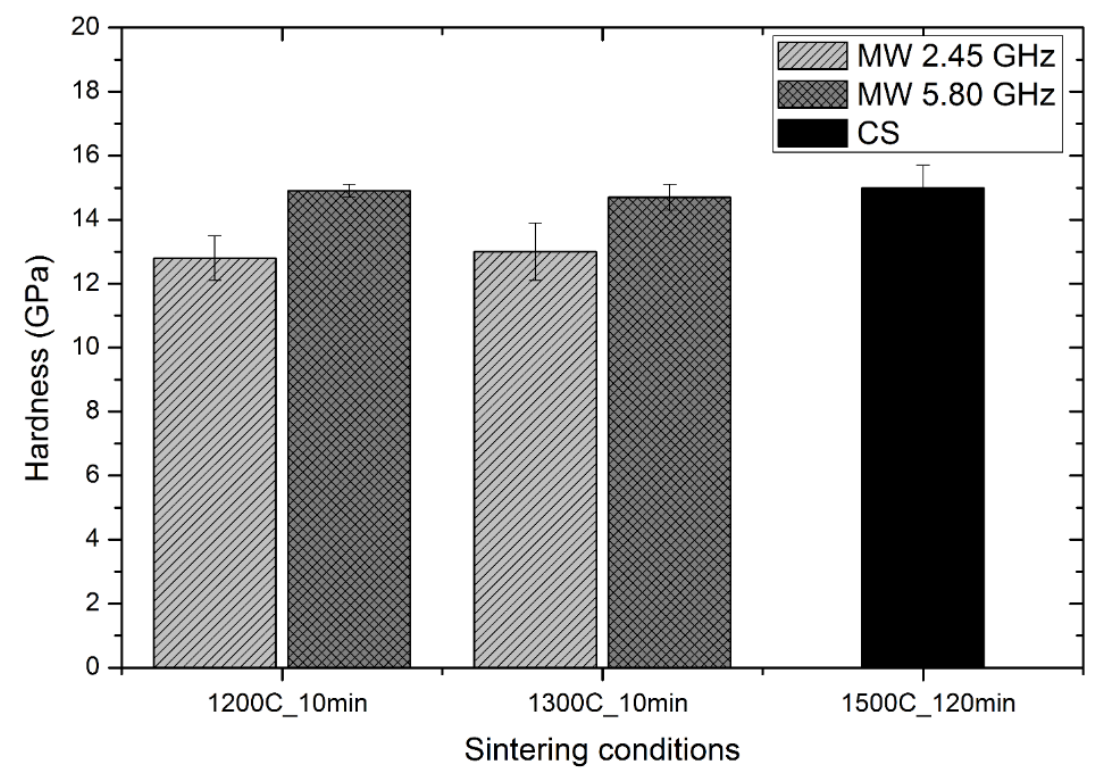

Figure 2. Hardness values of $10 \mathrm{Ce}-\mathrm{TZP} / \mathrm{Al}_{2} \mathrm{O}_{3}$ composites sintered at different temperatures by conventional and microwave as a function of frequency.

In the case of $10 \mathrm{Ce}-\mathrm{TZP} / \mathrm{Al}_{2} \mathrm{O}_{3}$ composite, the addition of ceria as stabilizer induces a considerable increase in its fracture toughness in comparison with yttria doped zirconia (Y-TZP) materials $[8,13]$, getting a material much more resistant to fracture, which is of vital importance when it is used for implant and prosthesis.

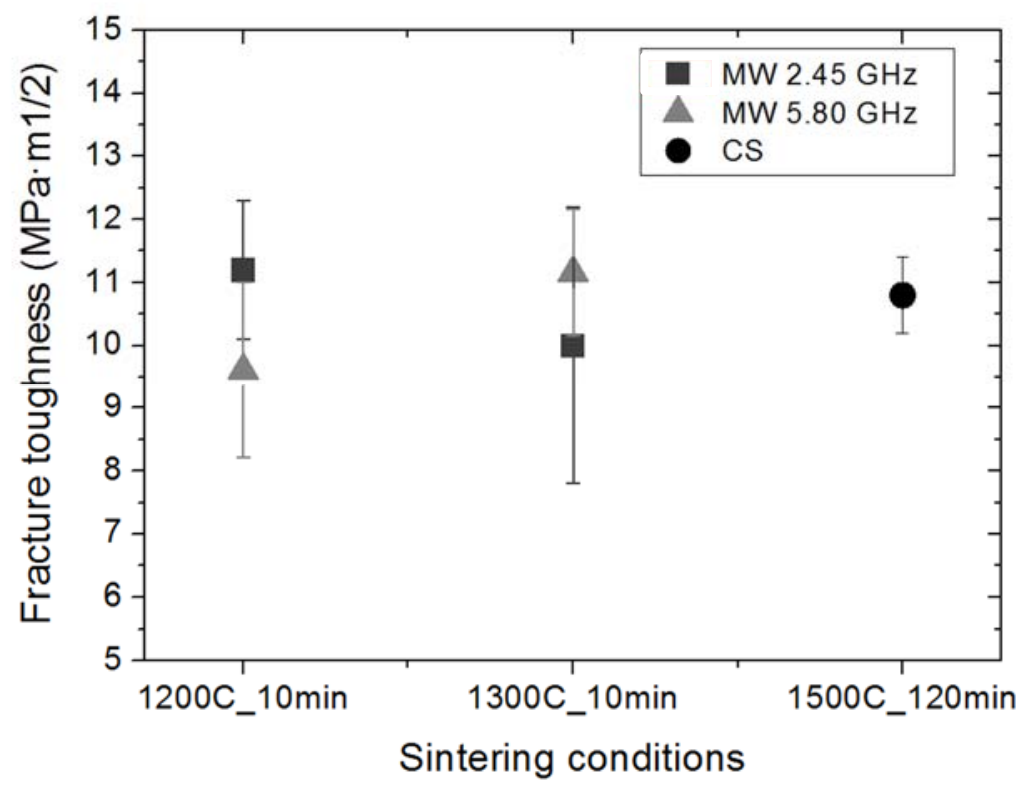

Figure 3. Fracture toughness values of $10 \mathrm{Ce}-\mathrm{TZP} / \mathrm{Al}_{2} \mathrm{O}_{3}$ composites sintered at different temperatures by conventional and microwave as a function of frequency. 


\section{CONCLUSIONS}

In this study, sintering behavior of $10 \mathrm{Ce}-\mathrm{TZP} / \mathrm{Al}_{2} \mathrm{O}_{3}$ composite is investigated through conventional and microwave sintering applying two different frequencies: $2.45 \mathrm{GHz}$ and $5.8 \mathrm{GHz}$. To the best knowledge, no studies have been found in the literature where the behavior of sintering in ceramic materials at high temperature is investigated and compared by using these frequencies.

The most remarkable result is that material sintered by MW has resulted in $\mathrm{H}$ and $\mathrm{K}_{\mathrm{IC}}$ high values at least comparable with those obtained by conventional oven. Furthermore, our composites present values within the admissible range for applications as implants and prosthesis.

Overall, microwave sintering demonstrated to be an exceptional alternative for sintering $10 \mathrm{Ce}-\mathrm{TZP} / \mathrm{Al}_{2} \mathrm{O}_{3}$ composite, due to the good mechanical properties and fine microstructure of resulting materials. In addition, this technology needs lower sintering temperatures and dwell time than conventional sintering, being able to reduce processing times and energy consumption and, consequently, microwave technique has a lower environmental impact.

\section{ACKNOWLEDGEMENTS}

The authors would like to thank the Valencia Government for financial support received for the project PROMETEU/2016/040. A. Borrell acknowledges the Spanish Ministry of Economy and Competitiveness for her RyC contract (RYC-2016-20915).

\section{REFERENCES}

[1] A.A. Almazdi et al. Applying microwave technology to sintering dental zirconia. Journal of Prosthetic Dentistry, 108, (2012), 304-309.

[2] R. Benavente et al. Microwave, Spark Plasma and Conventional Sintering to Obtain Controlled Thermal Expansion $\beta$-Eucryptite Materials. International Journal of Applied Ceramic Technology, 12, (2014), E187-E193.

[3] I. Denry, and J.A. Holloway. Ceramics for dental applications: A review. Materials, 3, (2010), 351-368.

[4] J.R. Kelly, and I. Denry. Stabilized zirconia as a structural ceramic: An overview. 24, (2008), 289-298.

[5] S. Lawson. Environmental degradation of zirconia ceramics. Journal of the European Ceramic Society, 15, (1995), 485-502.

[6] R.R. Mishra, and A.K. Sharma. Microwave-material interaction phenomena: Heating mechanisms, challenges and opportunities in material processing. Composites Part A: Applied Science and Manufacturing, 81, (2016), 78-97.

[7] C. Monaco et al. Microstructural study of microwave sintered zirconia for dental applications. Ceramics International, 41, (2014), 1255-1261.

[8] M. Nawa et al. Tough and Strong Ce-TZP/Alumina Nanocomposites Doped with Titania. Ceramics International, 24, (1998), 497-506.

[9] W.C. Oliver, and G.M. Pharr. An improved technique for determining hardness and elastic modulus using load and displacement sensing indentation experiments. Journal of Materials Research, 7, (1992), 1564-1583.

[10] Y. Pakhomov et al. Microwave dielectric properties of nanocomposite rare-earth titanates. International Journal of Applied Electromagnetics and Mechanics, 59, (2019), 137-144.

[11] Á. Presenda et al. Hydrothermal Degradation Behavior of Y-TZP Ceramics Sintered by Nonconventional Microwave Technology. Journal of the American Ceramic Society, 98, (2015), 3680-3689.

[12] Á. Presenda et al. Effect of microwave sintering on microstructure and mechanical properties in Y-TZP materials used for dental applications. Ceramics International, 41, (2015), 7125-7132.

[13] K. Tanaka et al. Phase stability after aging and its influence on pin-on-disk wear 
properties of $\mathrm{Ce}-\mathrm{TZP} / \mathrm{Al} 2 \mathrm{O} 3$ nanocomposite and conventional Y-TZP. Journal of biomedical materials research. Part A, 67, (2003), 200-207.

[14] M. Vallet-Regí. Ceramics for medical applications. Journal of the Chemical Society, Dalton Transactions, 1, (2001), 97-108.

[15] P. Veronesi et al. Energy Efficiency in the Microwave-Assisted Solid-State Synthesis of Cobalt Aluminate Pigment. Technologies, 5, 42, (2017). 